\title{
Editorial
}

\section{Second Conference Issue of Spectroscopy}

The First International Conference on Biomedical Spectroscopy, held in Cardiff, UK was a great success. This is the second volume containing papers that were presented at the conference. The first paper in this issue is an article by Professor Ozaki who presented a lecture in Cardiff, devoted to the memory of Professor Dennis Chapman FRS.

A Second International Conference on Biomedical Spectroscopy - From the Bench to the Clinic will be held in London, UK between 5-8 July 2003. The conference will cover all aspects of spectroscopy applied to solve biological problems. The particular focus of the conference will be the role of spectroscopy in health and disease, in the post-genomic era. It will discuss how spectroscopy plays an important role in not only diagnosis of disease processes but also in drug development. Scientists engaged in applying spectroscopy, in either the laboratory bench setting or in the clinic, are invited to take part and present their work. The deadline for Abstract submission is 31 May 2003. Papers presented at the conference will be published in a Special Conference issue of Spectroscopy, after appropriate reviewing. The deadline for paper submission is 8 July 2003.

Parvez I. Haris

Editor-in-Chief

Spectroscopy - An International Journal

E-mail: pharis@dmu.ac.uk 


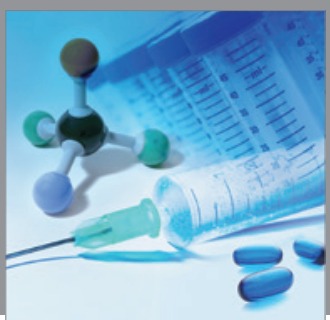

International Journal of

Medicinal Chemistry

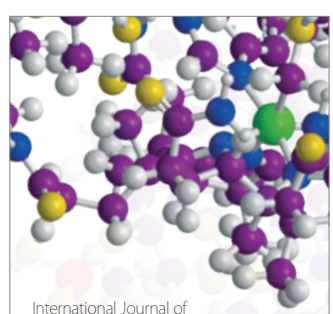

Carbohydrate Chemistry

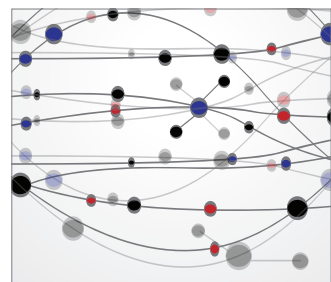

The Scientific World Journal
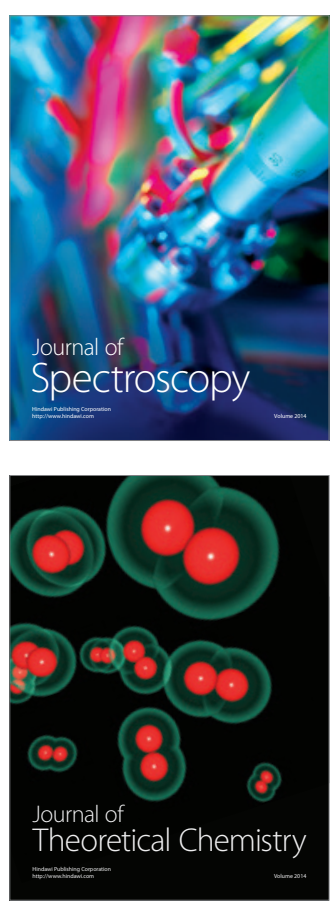
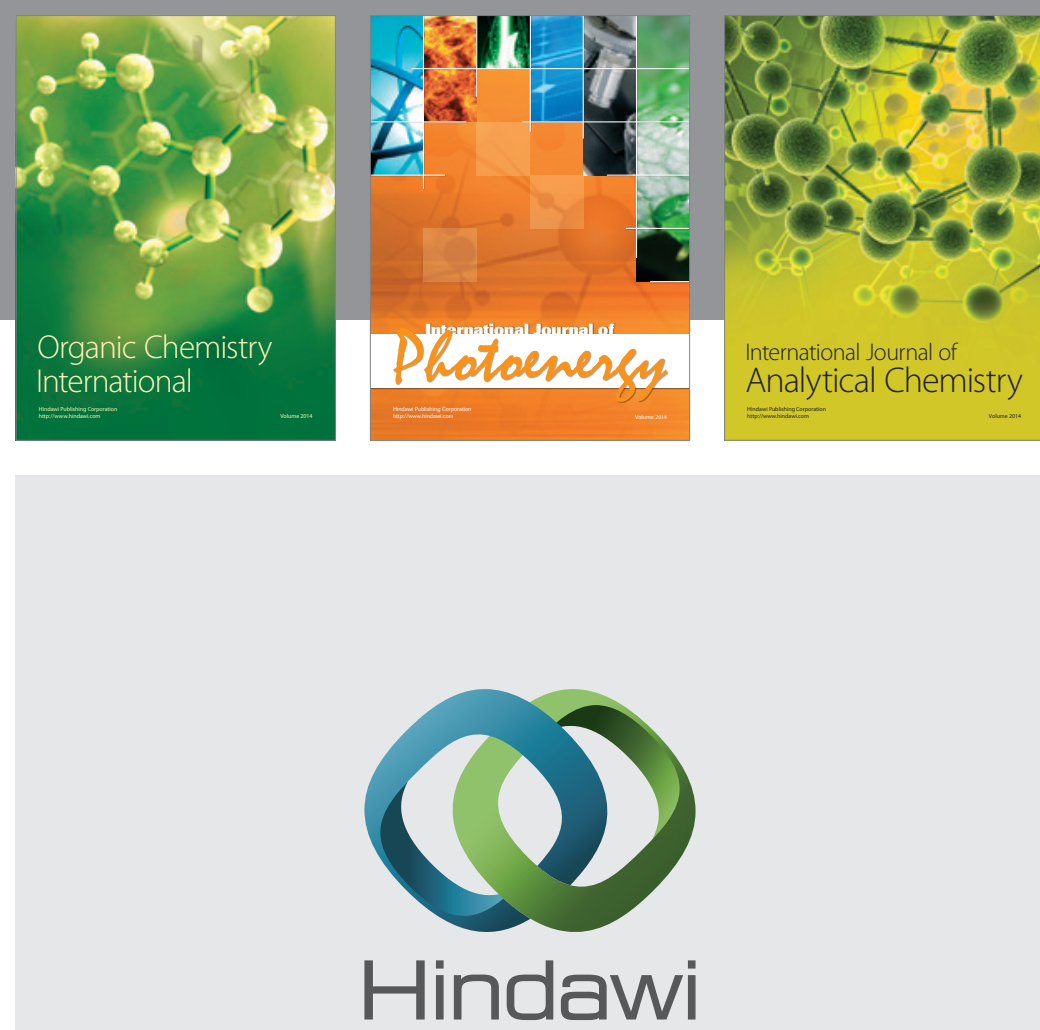

Submit your manuscripts at

http://www.hindawi.com
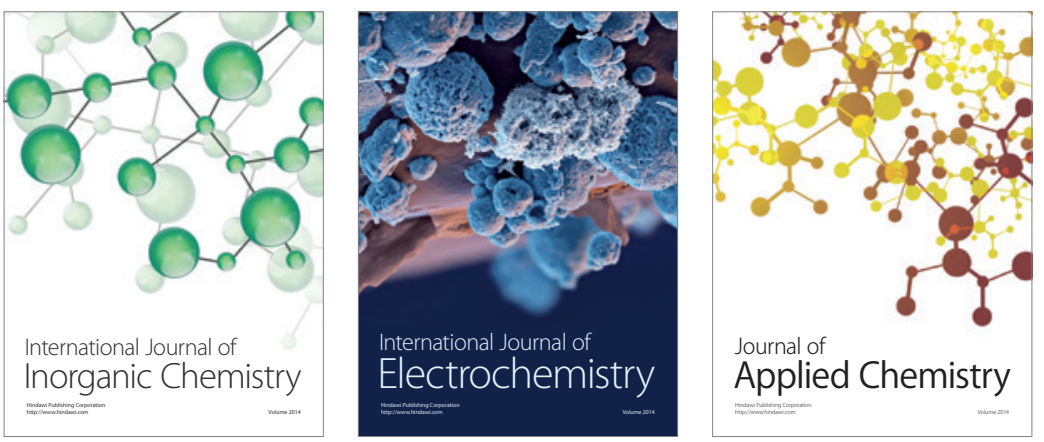

Journal of

Applied Chemistry
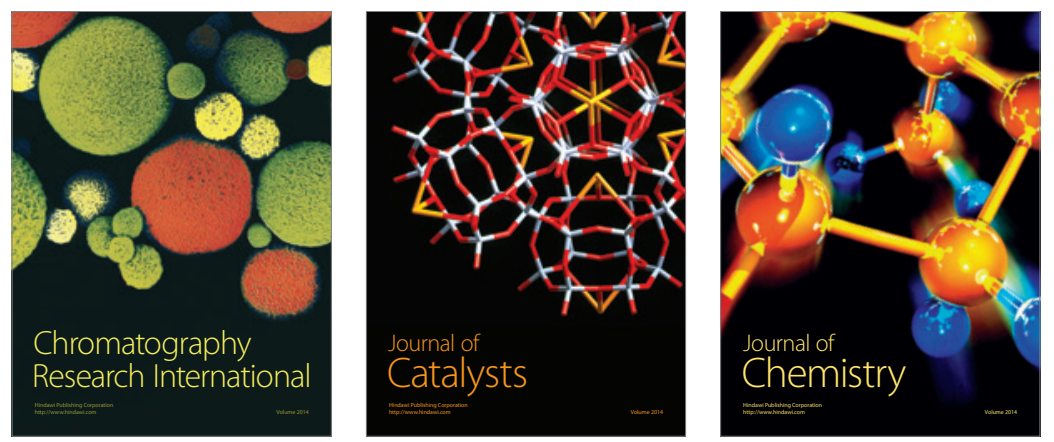
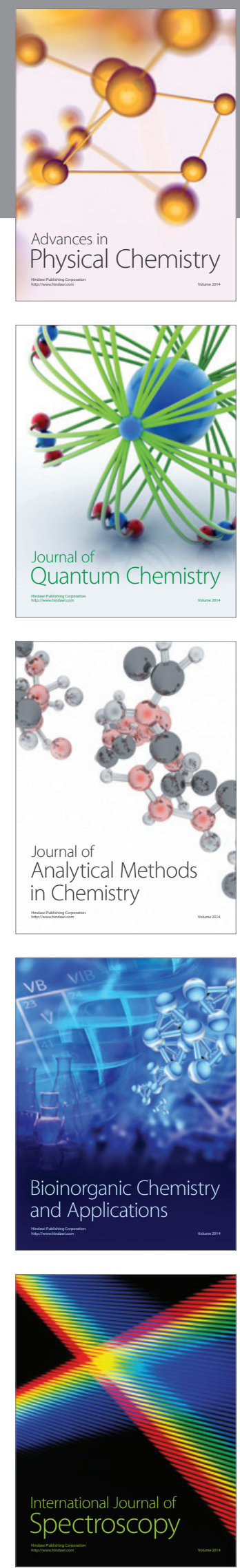